\title{
The impact of HIV infection on the presentation of lung cancer in South Africa
}

\author{
C F N Koegelenberg, ${ }^{1} \mathrm{MB} \mathrm{ChB}, \mathrm{MMed}(\mathrm{Int}), \mathrm{FCP}(\mathrm{SA}), \mathrm{FRCP}(\mathrm{UK})$, Cert Pulm (SA), PhD; T van der Made, ${ }^{1} \mathrm{MB}$ ChB; \\ J J Taljaard, ${ }^{2} \mathrm{MB}$ ChB, MMed (Int); E M Irusen, ${ }^{1} \mathrm{MB}$ ChB, FCP (SA), PhD \\ ${ }^{1}$ Division of Pulmonology, Department of Medicine, Stellenbosch University and Tygerberg Hospital, Cape Town, South Africa \\ ${ }^{2}$ Division of Infectious Diseases, Department of Medicine, Stellenbosch University and Tygerberg Hospital, Cape Town, South Africa
}

Corresponding author: C F N Koegelenberg (coeniefn@sun.ac.za)

Background. Despite the very high background prevalence of HIV and smoking-related diseases in sub-Saharan Africa, very little is known about the presentation of lung cancer in HIV-infected individuals.

Methods. We prospectively compared HIV-positive $(n=44)$ and HIV-negative lung cancer patients $(n=425)$ with regard to demographics, cell type, performance status and tumour node metastasis staging at initial presentation.

Results. HIV-positive patients were found to be younger than HIV-negative (mean 54.1 (standard deviation 8.4) years v. 60.5 (10) years, $p<0.01)$, more likely to have squamous cell carcinoma $(43.2 \%$ v. $30.1 \%, p=0.07)$ and significantly more likely to have a poor Eastern Cooperative Oncology Group (ECOG) performance status of $\geq 3$ ( $47.7 \%$ v. $29.4 \%, p=0.02)$. In the case of non-small cell-lung cancer, they were also significantly less likely to have early stage lung cancer $(0 \% \mathrm{v} .10 .3 \%, p=0.02)$ compared with HIV-negative patients.

Conclusions. HIV-positive lung cancer patients were younger, significantly more likely to have a poor performance status at presentation and significantly less likely to have early stage lung cancer when compared with HIV-negative patients.

S Afr Med J 2016;106(7):666-668. DOI:10.7196/SAMJ.2016v106i7.10737

The South African (SA) healthcare system has to deal with the largest HIV burden in the world, one of the highest incidences of TB, and a very high prevalence of smoking-related diseases. ${ }^{[1]}$ In fact, there is currently renewed interest in what has been termed the 'colliding epidemics' of HIV, tobacco smoking and TB. ${ }^{[1]}$

Two recent studies from SA showed similar changes in the predominant tissue type of lung cancer to that observed in other parts of the world, with adenocarcinoma being the most common form. ${ }^{[2,3]}$ Despite the very high background prevalence of HIV and smoking-related diseases in sub-Saharan Africa, and the fact the lung cancer has become the most common non-AIDS-defining cancer among HIV-positive individuals on antiretroviral (ARV) therapy, surprisingly little is known about the presentation of lung cancer in HIV-infected individuals in SA. ${ }^{[4]}$ Therefore, our objective was to compare HIV-positive and HIV-negative lung cancer patients with regard to demographics, cell type, performance status and umour node metastasis (TNM) staging at initial presentation.

\section{Methods}

We prospectively identified all cases of primary lung cancer presented at our weekly combined multidisciplinary chest oncology meeting from August 2013 to September 2015. Tygerberg Hospital is a 1380-bed tertiary facility in Cape Town, SA. It is one of two referral centres in the city and renders a tertiary service to a population of about 1.5 million, of whom 5.2\% (95\% confidence interval (CI) $3.4-7.8 \%$ ) are currently HIVinfected. This is considerably lower than the national average of $12.2 \% \cdot{ }^{[5]}$

We collected data on all patients with a known HIV status who had a tissue diagnosis of primary lung cancer and who underwent a staging computed tomography (CT) scan. Routine demographic and clinical data were collected, including the smoking status (to qualify as a smoker a patient had to have smoked at least 10 packyears per lifetime) and performance status according to the Eastern Cooperative Oncology Group (ECOG).
All patients were advised and counselled to undergo HIV testing, but the test was only performed on those who provided written informed consent. The CD4 count value recorded closest to time of lung cancer diagnosis was documented in all HIV-positive patients.

All patients had access to positron emission tomography-CT, bronchoscopy with endobronchial ultrasound, guided transbronchial needle aspiration with rapid onsite evaluation, transthoracic imageguided biopsy (ultrasound or CT) and related diagnostic techniques that were performed at the discretion of the treating physicians as per standard operating procedures. A combined panel of at least a pulmonologist, thoracic radiologist, thoracic surgeon, specialist oncologist and pathologist staged all patients as per the 2009 International Association for the Study of Lung Cancer TNM staging system.

Chi-square or Fisher's exact tests (where indicated) were performed on dichotomous categorical variables, and $t$-testing on continuous data.

\section{Resulits}

During the 2-year period, 467 of 609 (76.7\%) patients with lung cancer consented to an HIV test or were known to be HIVpositive at presentation. In total, 44 of 467 (9.4\%) were HIV-positive (Table 1). The CD4 count of HIV-positive patients ranged from 9 to 790 cells $/ \mathrm{mL}$ (mean 385 cells $/ \mathrm{mL}$ ).

HIV-positive patients (mean age 54.1 (standard deviation (SD) 8.4) years) were younger than HIV-negative patients (60.5 (10.0) years, $p<0.001$ ), with no significant difference in gender distribution or smoking prevalence (Table 1). Overall, adenocarcinoma was the most frequent form of lung cancer (48.9\%), followed by squamous cell carcinoma (29.7\%). In HIV-positive patients, however, squamous cell carcinoma was more common than adenocarcinoma $(43.2 \% \mathrm{v}$. $30.1 \%, p=0.07$ ).

Fifty-five of the 532 patients (10.3\%) with non-small-cell lung cancer (NSCLC) were staged as early stage disease (up to stage IIIA). 
Not a single HIV-positive patient had early stage lung cancer, compared with 38 of 369 confirmed HIV-negative patients with NSCLC ( $0 \%$ v. $10.3 \%, p=0.02)$.

HIV-positive patients were also more likely to have a poor performance status (ECOG 3 and 4$)$ at presentation $(47.7 \% \mathrm{v}$. $29.4 \%, p=0.02$ ).

\section{Discussion}

In this prospective, observational study in patients with lung cancer, we found that HIV-positive patients were younger, more likely to have squamous cell carcinoma and significantly more likely to have a poor ECOG performance status of $\geq 3$ at presentation. Moreover, in the case of NSCLC, they were significantly less likely to have early stage lung cancer at presentation when compared with HIV-negative patients.

Although lung cancer is currently the most common non-AIDS-defining cancer among HIV-positive individuals, the exact role of the virus in the pathogenesis of lung cancer remains uncertain. ${ }^{[4]}$ It has been postulated that HIV may have a direct oncogenic role. ${ }^{[6]}$ Some experimental data suggest that the HIV trans-activator of transcription (tat) gene product may modulate expression of growth-related genes. Other potential mechanisms include accelerated lung damage associated with HIV-related infections and an increase in susceptibility to tobacco carcinogens through genomic instability. ${ }^{[7]}$

Sigel et al. ${ }^{[4]}$ analysed data from large US registries to calculate incidence rates of lung cancer in order to determine incidence rate ratios (IRRs), adjusting for age, sex, race/ethnicity, smoking prevalence, previous bacterial pneumonia and chronic obstructive pulmonary disease. The incidence rate of lung cancer in HIV-positive patients was 204 v. 119 cases per 100000 person-years in uninfected patients, with an IRR of 1.7 (95\% CI 1.5 - 1.9), arguably providing the strongest epidemiological evidence to date in favour of HIV infection being viewed as an independent risk factor for lung cancer. ${ }^{[4]}$

In an earlier study, also performed on large US registries, Shiels et al. ${ }^{[7]}$ found that the proportion of person-time contributed by older persons was far smaller in the AIDS population (1.5\%) than in the general population (12.5\%). As a result, the ages at diagnosis for most types of cancer were $\sim 20$ years younger among persons with AIDS. However, after adjustment for differences in the populations at risk, the median ages at diagnosis in the AIDS and general populations did not differ for most types of

Table 1. Demographics, cell types, stage and performance status for all lung cancer patients $(n=610)$

\begin{tabular}{|c|c|c|c|c|}
\hline & $\begin{array}{l}\text { All } \\
(N=610)^{*}\end{array}$ & $\begin{array}{l}\text { HIV-negative } \\
(n=425)\end{array}$ & $\begin{array}{l}\text { HIV-positive } \\
(n=44)\end{array}$ & $p$-value ${ }^{\dagger}$ \\
\hline \multicolumn{5}{|l|}{ Demographics } \\
\hline Age (years), mean (SD) & $59.9(10.1)$ & $60.5(10.0)$ & $54.1(8.4)$ & $<0.001$ \\
\hline Gender (male), $n(\%)$ & $372(61.0)$ & $252(59.3)$ & $29(65.9)$ & 0.42 \\
\hline Smokers, $n(\%)$ & $557(91.3)$ & $389(91.5)$ & $40(90.9)$ & 1 \\
\hline $\begin{array}{l}\mathrm{CD} 4 \text { count }\left(\text { cells } / \mathrm{mm}^{3}\right) \text {, mean } \\
\text { (SD) }\end{array}$ & - & - & $385(207)$ & - \\
\hline AIDS, $n(\%)$ & $9(1.5)$ & $0(0)$ & $9(20.5)$ & - \\
\hline \multicolumn{5}{|l|}{ Cell type, $n(\%)$} \\
\hline \multicolumn{5}{|l|}{ NSCLC } \\
\hline Adenocarcinoma & $298(48.9)$ & $210(49.4)$ & $17(38.7)$ & 0.21 \\
\hline Squamous cell carcinoma & $181(29.7)$ & $128(30.1)$ & $19(43.2)$ & 0.07 \\
\hline Poorly differentiated & $28(4.6)$ & $18(4.2)$ & $2(4.5)$ & 1 \\
\hline Other & $25(4.1)$ & $13(3.1)$ & $2(4.5)$ & 0.64 \\
\hline SCLC & $78(12.8)$ & $56(13.2)$ & $4(9.1)$ & 0.64 \\
\hline \multicolumn{5}{|l|}{ Stage, $n(\%)$} \\
\hline \multicolumn{5}{|l|}{ NSCLC } \\
\hline I & $7(1.3)$ & $6(1.6)$ & $0(0)$ & \\
\hline II & $15(2.8)$ & $9(2.4)$ & $0(0)$ & \\
\hline IIIA & $33(6.2)$ & $23(6.2)$ & $0(0)$ & \\
\hline IIIB & $115(21.6)$ & $85(23)$ & $8(80)$ & \\
\hline IV & $362(59.3)$ & $246(66.7)$ & $32(20)$ & $0.02^{\ddagger}$ \\
\hline \multicolumn{5}{|l|}{ SCLC } \\
\hline Limited & $10(12.8)$ & $6(10.7)$ & $1(25)$ & \\
\hline Extensive & $68(87.2)$ & $50(89.3)$ & $3(75)$ & - \\
\hline \multicolumn{5}{|l|}{ ECOG performance status } \\
\hline $0-2$ & $411(67.4)$ & $300(70.6)$ & $23(52.3)$ & \\
\hline $3-4$ & $199(32.6)$ & $125(29.4)$ & $21(47.7)$ & 0.02 \\
\hline
\end{tabular}

cancer, with the exceptions of lung (median 50 v. 54 years) and anal cancer (median 42 v. 45 years). ${ }^{[6]}$

Although earlier reports have suggested that that a higher prevalence of smoking may be to blame for the increased incidence of lung cancer in HIV-positive individuals, there are currently very few data to support this. ${ }^{[4]}$ We found no difference in smoking status between HIV-positive and negative participants.

We observed statistically significant and clinically relevant differences between HIV-positive and HIV-negative patients with regard to their performance status and stage at presentation. All patients with NSCLC presented with advanced cancer, and approximately half had a poor ECOG performance status of $\geq 3$, suggesting that the
HIV infection adversely affected the prognosis of lung cancer.

Contrary to most published series, we observed a trend towards squamous cell carcinoma as the most common tissue type in HIV-positive patients. Unlike anal cancer, where an identifiable infection such as human papillomavirus is involved in carcinogenesis, no co-infective contributor has been identified in lung cancer, making this observation difficult to elucidate. ${ }^{[6]}$ Our data also confirmed previous observations that the degree of immunosuppression (as judged by viral load or CD4 count) seems to have little or no impact on the risk for lung cancer. ${ }^{[4,6]}$

A limitation of our study is the fact that we did not specifically document socioeconomic status, level of education and 
substance abuse, all of which may be viewed as potential confounders that may have influenced the perceived late presentation and poor prognosis of the HIV-positive cohort.

\section{Conclusion}

We found HIV-positive lung cancer patients were younger, significantly more likely to have a poor ECOG performance status of $\geq 3$ at presentation and significantly less likely to have early stage lung cancer when compared with HIV-negative patients. The numbers of HIV-positive patients with lung cancer will most likely rise considerably over the next 2 decades owing to improved survival of patients on combination ARV therapy, resulting in an aging HIVpositive population with a relatively higher risk for lung cancer. This highlights the importance of further research on lung cancer in HIV, especially in the setting of 'colliding epidemics'.
1. Van Zyl Smit RN, Pai M, Yew WW, et al. Global lung health: The colliding epidemics of tuberculosis, tobacco smoking, HIV and COPD. Eur Respir J 2010;35(1):27-33. DOI:10.1183/09031936.00072909

2. Nanguzgambo AB, Aubeelack K, von Groote-Bidlingmaier F, et al. Radiologic features, staging, and operability of primary lung cancer in the Western Cape, South Africa: A 1-year retrospective study. J Thorac Oncol 2011;6(2):343-350. DOI:10.1097/TTO.0b013e3181fd40ec

3. Koegelenberg CF, Aubeelack K, Nanguzgambo AB, et al. Adenocarcinoma the most common cell type 3. Koegelenberg $\mathrm{CF}$, Aubeelack $\mathrm{K}$, Nanguzgambo AB, et al. Adenocarcinoma the most common cell type
in patients presenting with primary lung cancer in the Western Cape. S Afr Med J 2011;101(5):321. DOI:10.7196/SAMJ.4554

4. Sigel K, Wisnivesky J, Gordon K, et al. HIV as an independent risk factor for incident lung cancer. AIDS 2012;26(8):1017-1025. DOI:10.1097/QAD.0b013e328352dlad

5. Shisana, O, Rehle, T, Simbayi LC, et al. South African National HIV Prevalence, Incidence and Behaviour Survey, 2012. Cape Town: Human Sciences Research Council Press, 2014. http://www.hsrc. ac.za/en/research-data/view/6871 (accessed 8 December 2015).

6. Kirk GD, Merlo CA, Lung HIV Study. HIV infection in the etiology of lung cancer: Confounding causality, and consequences. Proc Am Thorac Soc 2011;8(3):326-332. DOI:10.1513/pats.201009-061WR 7. Shiels MS, Pfeiffer RM, Engels EA. Age at cancer diagnosis among persons with AIDS in the United States. Ann Intern Med 2010;153(7):452-460. DOI:10.7326/0003-4819-153-7-201010050-00008 